\title{
Ozonioterapia como opção de tratamento contra COVID-19: uma revisão de literatura
}

\author{
Ozone therapy as a treatment option against COVID-19: a literature review \\ La ozonioterapia como opción de tratamiento contra COVID-19: una revisión de la literatura
}

Recebido: 29/09/2021 | Revisado: 09/10/2021 | Aceito: 16/10/2021 | Publicado: 18/10/2021

Renata Braga Barbosa
ORCID: https://orcid.org/0000-0001-5315-9793
Escola Superior da Amazônia, Brasil
E-mail: renatta.bragaa@ gmail.com
Rubens do Espírito Santo
ORCID: https://orcid.org/0000-0003-1598-6952
Escola Superior da Amazônia, Brasil
E-mail:rubinhocfc@ @hotmail.com
Zilma Miranda Navegante
ORCID: https://orcid.org/0000-0003-1105-0225
Escola Superior da Amazônia, Brasil
E-mail: zilmanav@ @otmail.com
Sonia Lhamas Santana Santos
ORCID: https://orcid.org/0000-0001-6345-0728
Escola Superior da Amazônia, Brasil
E-mail: soninhalhamas@ @otmail.com
Juan Gonzalo Bardález Rivera
ORCID: https://orcid.org/0000-0003-1737-6947
Escola Superior da Amazônia, Brasil
E-mail: jgrivera@bol.com.br
Antonio Taylon Aguiar Gomes
ORCID: https://orcid.org/0000-0003-2869-553X
Escola Superior da Amazônia, Brasil
E-mail: t4ylon@gmail.com

\section{Resumo}

A ozonioterapia é um tratamento que usa o gás medicinal ozonizado, com uma mistura de ozônio e oxigênio puro em concentrações de 5\% e 95\% respectivamente. Esta terapia tem consideráveis e expressivos benefícios quando administrada em doses adequadas, por ter uma forte ação antioxidante, bactericida, fungicida e antiviral. Dentre as ações antivirais, a ozonioterapia possui interessantes características para combater o coronavírus. Neste sentido, essa pesquisa pretende realizar uma revisão de literatura da aplicação da ozonioterapia no tratamento da infecção por COVID-19. Este estudo trata-se de uma revisão bibliográfica integrativa do tipo exploratória de caráter qualitativa, com os dados coletados em artigos, monografias e legislações brasileiras no período de março de 2011 a março de 2021. Através dos resultados, foi possível perceber que a ozonioterapia pode ser utilizada como monoterapia ou adjuvante em associação com outros fármacos no tratamento contra a COVID-19, visto que após o uso desta terapia constatou-se uma melhora no quadro clínico, nos marcadores bioquímicos de inflamação e radiológicos sem apresentar efeitos colaterais, tornandose um tratamento efetivo e benéfico aos pacientes. Este trabalho corrobora com a ampliação sobre o entendimento e propagação da ozonioterapia e relata a relevância social e científica do uso da ozonioterapia no tratamento da COVID19.

Palavras-chave: Ozônio; Ozonioterapia; COVID-19; Coronavírus.

\begin{abstract}
Ozone therapy is a treatment that uses ozonized medicinal gas, with a mixture of ozone and pure oxygen in concentrations of 5\% and $95 \%$ respectively. This therapy has considerable and expressive benefits when administered in adequate doses, as it has a strong antioxidant, bactericidal, fungicidal and antiviral action. Among the antiviral actions, ozone therapy has interesting characteristics to fight the coronavirus. In this sense, this research intends to carry out a literature review on the application of ozone therapy in the treatment of COVID-19 infection. This study is an integrative bibliographic review of the exploratory type of qualitative character, with data collected in articles, monographs and Brazilian legislation from March 2011 to March 2021. Through the results, it was possible to see that ozone therapy can be used as monotherapy or adjuvant in association with other drugs in the treatment against COVID19 , since after the use of this therapy there was an improvement in the clinical picture, in the biochemical markers of inflammation and radiological without presenting side effects, becoming effective and beneficial treatment for patients. This work corroborates the expansion of the understanding and spread of ozone therapy and reports the social and scientific relevance of the use of ozone therapy in the treatment of COVID-19.
\end{abstract}

Keywords: Ozone; Ozone therapy; COVID-19; Coronavirus. 


\begin{abstract}
Resumen
La ozonoterapia es un tratamiento que utiliza gas medicinal ozonizado, con una mezcla de ozono y oxígeno puro en concentraciones de 5\% y 95\% respectivamente. Esta terapia tiene beneficios considerables y expresivos cuando se administra en dosis adecuadas, ya que tiene una fuerte acción antioxidante, bactericida, fungicida y antiviral. Entre las acciones antivirales, la ozonoterapia tiene características interesantes para combatir el coronavirus. En este sentido, esta investigación pretende realizar una revisión de la literatura sobre la aplicación de la ozonoterapia en el tratamiento de la infección por COVID-19. Este estudio es una revisión bibliográfica integradora de tipo exploratorio de carácter cualitativo, con datos recolectados en artículos, monografías y legislación brasileña desde marzo de 2011 a marzo de 2021. A través de los resultados, se pudo ver que la ozonoterapia puede ser utilizada como monoterapia o adyuvante en asociación con otros fármacos en el tratamiento frente a COVID-19, ya que tras el uso de esta terapia se produjo una mejoría en el cuadro clínico, en los marcadores bioquímicos de inflamación y radiológicos sin presentar efectos secundarios, convirtiéndose en un tratamiento eficaz y beneficioso para los pacientes. Este trabajo corrobora la expansión del conocimiento y la difusión de la ozonoterapia y reporta la relevancia social y científica del uso de la ozonoterapia en el tratamiento del COVID-19.
\end{abstract}

Palabras clave: Ozono; Ozonoterapia; COVID-19; Coronavirus.

\title{
1 Introdução
}

Ozônio é um gás constituído estruturalmente por três átomos de oxigênio distribuído de forma cíclica, podendo ser encontrado de modo espontâneo na atmosfera em torno do planeta Terra, ao qual serve como escudo para prevenção de danos da radiação ultravioleta. O ozônio tem um alto poder de oxidação, muito maior que o oxigênio, e por essa razão tem forte instabilidade em elevadas concentrações (Merhi et al., 2019).

A ozonioterapia é um tratamento que usa o gás medicinal ozonizado, com uma mistura de ozônio e oxigênio puro em concentrações de 5\% e 95\% respectivamente. O objetivo do tratamento é induzir o estresse oxidativo agudo equilibrado, apropriado e momentâneo, sem exceder o potencial antioxidante do organismo. O ozônio medicinal causa múltiplas ações no organismo, tais como: aumento na oxigenação, microcirculação sanguínea para tecidos isquêmicos, melhorando o metabolismo por inteiro (Páez et al., 2020; Silva et al., 2018).

A ozonioterapia foi inclusa em 2018, pelo Ministério da Saúde, na Política Nacional de Práticas Integrativas e Complementares (PNPIC). A terapia é abrangente para diferentes finalidades e favorece algumas classes de profissionais da área da saúde, dentre eles, odontólogos, fisioterapeutas, enfermeiros, biomédicos e farmacêuticos. Recentemente, o Conselho Federal de Farmácia reafirmou através da divulgação de um comunicado referente à certificação da normatização do profissional farmacêutico com a ozonioterapia (Ferreira et al., 2020; Ornelas et al., 2020).

Diante a esse documento o farmacêutico é amparado pela Resolução № 685 , de 30 de janeiro de 2020, porém muitos não possuem os conhecimentos viáveis do uso da ozonioterapia para tratamento de inúmeras patologias. Diante disso, foi levantado o questionamento de quais os possíveis benefícios e adversidades na utilização da ozonioterapia em alguns distúrbios patológicos. Visto que o ozônio medicinal é considerado como medicamento ou preparação magistral, se faz necessário um profissional com habilidades para monitorar a sua utilização. Assim sendo o profissional farmacêutico é indispensável para avaliar o objetivo do uso, modo de administração, dosagem e as respostas e alterações decorrentes dessa terapia (Brasil, 2020).

Uma vez que esta terapia tem consideráveis e expressivos benefícios quando administrada em doses adequadas, por ter uma forte ação pro-oxidante, cicatrização de feridas, bactericida, fungicida e antiviral e como malefício em altas dosagens estimula o estresse oxidativo grave (Galiè et al., 2019).

Considerando o baixo custo do tratamento e dos grandes resultados em que ele oferece, ainda há grande resistência por parte da indústria farmacêutica, por falta de incentivo nas pesquisas e até mesmo a difícil aceitação do paciente por conta da via e forma de administração, apesar de serem bastante satisfatórios os resultados obtidos com essa terapia (Sagai \& Bocci, 2011).

Neste sentido, a atual proposta pretende informar a relevância da ozonioterapia tendo em foco sua aplicabilidade no combate ao novo Coronavírus. Além de explanar sobre a ozonioterapia, esclarecer sobre o tratamento contra a COVID-19, 
explicar a relação do estresse oxidativo na ozonioterapia para o tratamento contra a COVID-19 e descrever o papel do farmacêutico junto aos demais profissionais de saúde na aplicação da ozonioterapia.

De acordo com os estudos realizados com o surgimento e aumento de inúmeras patologias, há uma busca por novas terapias sem grandes efeitos adversos significativos. Com isso, a ozonioterapia torna-se uma alternativa eficiente com baixo custo, poucos efeitos adversos e baixa toxicidade, quando administrada de maneira adequada podendo ser facilmente realizada por profissionais legalmente licenciados. Desse modo, pretendemos é possível ter sucesso com terapias complementares como a ozonioterapia, sendo uma alternativa de amplo espectro em tratamento de diversas patologias, dentre elas, a do vírus da COVID19 (Rowen, 2019).

\section{Metodologia}

\subsection{Tipo de estudo}

O presente estudo trata-se de uma revisão bibliográfica integrativa do tipo exploratória de caráter qualitativa usando artigos e monografias indexados na seguinte base de dados. A pesquisa exploratória é realizada quando se tem maior familiarizada com o tema e assume a forma de estudo de caso e pesquisas bibliográficas (Souza et al., 2010). Nesse estudo não usaremos métodos e técnicas estatísticas por isso o caráter qualitativo (Piovesan \& Temporini, 1995).

\subsection{Local da pesquisa}

A bases de dados utilizadas foram a PubMed, a qual é um serviço ofertado pela National Librany of Medicine (NLM), o acervo SciELO (Scientific Electronic Library Online), além de artigos presentes na Biblioteca Virtual do Google Acadêmico, em legislações relacionado ao uso da ozonioterapia e em repositórios, como Unesp (Universidade Estadual Paulista) e UFSC (Universidade Federal de Santa Catarina). Utilizando como busca os seguintes descritores ozonioterapia, tratamento covid, ozone therapy, covid e ozone.

\subsection{Período do estudo}

Os artigos selecionados são compreendidos no período março de 2011 a março de 2021, usando os idiomas português, inglês e espanhol.

\subsection{Critério de inclusão e exclusão}

O critério de inclusão dos artigos e monografias foram relacionados ao uso da ozonioterapia como uma alternativa terapêutica para uso em patologias e na covid 19, sendo excluídos artigos que não estejam relacionados ao uso da ozonioterapia com patologia e no coronavírus, que esteja relacionada com outros temas pertencentes ao ozônio, além de literaturas duplicadas, falta de acesso gratuito ao texto completo e de estudos com evidências cientificas inadequadas.

\section{Resultados e Discussões}

Foram realizadas as leituras dos resumos dos estudos para selecionar os que se adequam ao tema desta pesquisa, ou seja: estudos que tratem sobre a ozonioterapia no tratamento complementar da COVID-19 e os profissionais de saúde envolvidos nesta terapia. Esta seleção reduziu o total da amostra para 13 publicações, listadas no Quadro 1. A análise dos artigos selecionados possibilitou a extração de informações pertinentes aos objetivos desta revisão, as quais serão discutidas a seguir. 
Quadro 1 - Levantamento Bibliográfico.

\begin{tabular}{|c|c|c|c|}
\hline AUTORES, ANO & TÍTULO & IDIOMA & RESULTADOS \\
\hline (Ranaldi et al., 2020) & $\begin{array}{l}\text { Rationale for ozone-therapy as } \\
\text { an adjuvant therapy in COVID- } \\
\text { 19: a narrative review }\end{array}$ & Inglês & $\begin{array}{c}\text { Ozônio medicinal pode cooperar na redução da } \\
\text { inflamação pulmonar, desacelerar a multiplicação viral, } \\
\text { controlar o fluxo pulmonar e evitar a trombose } \\
\text { microvascular. }\end{array}$ \\
\hline (Cattel et al., 2021) & $\begin{array}{l}\text { Ozone therapy in COVID-19: A } \\
\text { narrative review }\end{array}$ & Inglês & $\begin{array}{l}\text { Demonstram benefícios da ozonioterapia como controle } \\
\text { da inflamação, ativação da imunidade e redução da ação } \\
\text { viral e previne a manifestações coronarianas agudas. }\end{array}$ \\
\hline (Shah et al., 2021) & $\begin{array}{l}\text { Safety and efficacy of ozone } \\
\text { therapy in mild to moderate } \\
\text { COVID-19 patients: A phase } \\
1 / 11 \text { randomized control trial } \\
\text { (SEOT study) }\end{array}$ & Inglês & $\begin{array}{c}\text { A terapia com ozônio no tratamento adjuvante da } \\
\text { COVID-19 diminuiu a mortalidade, além de reduzir o } \\
\text { tempo para recuperação dos pacientes em estados leves a } \\
\text { moderados. }\end{array}$ \\
\hline $\begin{array}{l}\text { (Hernández et al., } \\
\text { 2021). }\end{array}$ & $\begin{array}{l}\text { Ozone therapy for patients with } \\
\text { COVID-19 pneumonia: } \\
\text { Preliminary report of a } \\
\text { prospective case-control study }\end{array}$ & Inglês & $\begin{array}{l}\text { Aplicação da auto-hemoterapia recupera pacientes } \\
\text { infectados por COVID-19, com pneumonia grave em } \\
\text { menos tempo que o tratamento padrão. }\end{array}$ \\
\hline $\begin{array}{l}\text { (Peña-Lora et al., } \\
\text { 2020). }\end{array}$ & $\begin{array}{l}\text { Uso de ozonioterapia rectal en } \\
\text { paciente anciana con neumonía } \\
\text { grave por COVID-19 }\end{array}$ & Espanhol & $\begin{array}{l}\text { A melhora de paciente com pneumonia devido a COVID- } \\
\text { 19, após sessões de Ozonioterapia via retal. }\end{array}$ \\
\hline $\begin{array}{l}\text { (Fernández-Cuadros et } \\
\text { al., 2020)b }\end{array}$ & $\begin{array}{l}\text { Effect of Rectal Ozone (O3) in } \\
\text { Severe COVID-19 Pneumonia: } \\
\text { Preliminary Results }\end{array}$ & Inglês & $\begin{array}{l}\text { Eficácia do ozônio retal em pacientes com pneumonia } \\
\text { grave por COVID-19 com melhora dos sintomas clínicos, } \\
\text { bioquímicos e radiológicos com resultados preliminares } \\
\text { em uma pequena serie de pacientes. }\end{array}$ \\
\hline $\begin{array}{l}\text { (Martínez-Sánchez et } \\
\text { al., 2020) }\end{array}$ & $\begin{array}{l}\text { Potential Cytoprotective } \\
\text { Activity of Ozone Therapy in } \\
\text { SARS-CoV-2/COVID-19 } \\
\end{array}$ & Inglês & $\begin{array}{l}\text { A modulação das vias NF- } \kappa \mathrm{B} / \mathrm{Nrf} 2 \text {, através da } \\
\text { ozonioterapia tem impacto na citoproteção e bloqueio da } \\
\text { replicação viral no SARS-CoV-2. }\end{array}$ \\
\hline (Izadi et al., 2021) & $\begin{array}{l}\text { Ozone therapy for the treatment } \\
\text { of COVID-19 pneumonia: A } \\
\text { scoping review }\end{array}$ & Inglês & $\begin{array}{l}\text { A Ozonioterapia contribui para conter o estresse } \\
\text { oxidativo celular da pneumonia por COVID-19. }\end{array}$ \\
\hline (Páez et al., 2020) & $\begin{array}{l}\text { OZONIOTERAPIA E SEUS } \\
\text { ASPECTOS } \\
\text { CONTROVERTIDOS }\end{array}$ & Português & $\begin{array}{l}\text { Políticas governamentais são necessários para assegurar } \\
\text { que todos parâmetros de aplicação da Ozonioterapia, } \\
\text { assim como, atribuições de profissionais habilitados a fim } \\
\text { de se evitar eventuais riscos à saúde de usuários. }\end{array}$ \\
\hline$(\mathrm{ABOZ}, 2019)$ & $\begin{array}{l}\text { Os avanços da regulamentação } \\
\text { da Ozonioterapia nos Conselhos } \\
\text { de Classes }\end{array}$ & Português & $\begin{array}{l}\text { Conselhos de classes profissionais atualmente tem sido } \\
\text { primordial para definir normativas correspondentes para } \\
\text { exercício de cada profissão. }\end{array}$ \\
\hline (Brasil, 2020) & $\begin{array}{l}\text { Projeto autoriza uso da } \\
\text { ozonioterapia como tratamento } \\
\text { complementar para Covid-19. }\end{array}$ & Português & $\begin{array}{c}\text { Projeto de lei } 1383 / 20 \text { sanciona a ozonioterapia como } \\
\text { terapia médica complementar em casos de COVID-19 a } \\
\text { nível experimental, projeto este que ainda necessita de } \\
\text { aprovação. }\end{array}$ \\
\hline$(\mathrm{ABOZ}, 2020)$ & $\begin{array}{l}\text { Os avanços da regulamentação } \\
\text { da Ozonioterapia nos Conselhos } \\
\text { de Classes. }\end{array}$ & Português & $\begin{array}{l}\text { Fisioterapeutas e Farmacêuticos autorizados a prática da } \\
\text { ozonioterapia pelos respectivos conselhos de classes. }\end{array}$ \\
\hline (Lima, 2021) & $\begin{array}{l}\text { Ozonioterapia: Uma abordagem } \\
\text { profissional e a aplicação da } \\
\text { técnica em pacientes no } \\
\text { Município de Patos/PB }\end{array}$ & Português & $\begin{array}{l}\text { Pesquisa no município de Patos/PB ratifica que } \\
\text { profissionais da USB pouco conheciam a aplicação da } \\
\text { ozonioterapia e nunca haviam utilizado a técnica. }\end{array}$ \\
\hline
\end{tabular}

Fonte: Autores.

As manifestações clínicas causadas pela infecção da COVID-19 ainda não estão bem claras, pois os sintomas relatados variam de leves a graves, e em alguns casos até resultam em morte do paciente. O SARS-CoV-2 é um vírus novo, e por conta disso, não há terapia comprovada contra ele. Várias opções terapêuticas foram testadas, como terapias de suporte (esteroides, heparina) ou como tratamento antiviral ou imunomodulador (remdesivir, hidroxicloroquina, tocilizumab, plasma hiper imune). Neste contexto, o emprego da terapia com ozônio é interessante pelo seu papel imunológico com a modulação de citocinas e 
interferons, incluindo a indução de interferon gama. Desta forma, esta terapia pode atuar como monoterapia ou como um complemento aos regimes de tratamento padrão, contra a COVID-19 (Cattel et al., 2021).

Estudo feito por Ranaldi et al. (2020) constataram que a utilização coadjuvante da ozonioterapia na COVID-19 através da autohemoinfusão ou infusão retal, é capaz de oxigenar melhor os tecidos e equilibrar as reações do sistema imune, pois impede a cascata de liberação de citocinas pelo organismo e regula a microcirculação pulmonar, protegendo e dificultando a hipertrofia muscular, especialmente na fase inicial da infecção pelo vírus.

No estudo de Cattel et al. (2021) foi demonstrado que a terapia com ozônio possui diversos benefícios, entre os quais, previnem as manifestações coronarianas agudas e anomalias ocasionadas pela reperfusão da isquemia. Os autores indicam que o tratamento com ozônio é inovador para a imunoterapia, visto que a sua utilização em associação com outros fármacos antivirais em pacientes infectados com COVID-19 é capaz de torna-se efetivo, benéfico e coadjuvante.

Shah et al. (2021) verificou que, em seu estudo de controle randomizado feito em dois grupos paralelos, um grupo recebeu o ozônio medicinal por insuflação retal e auto-hemoterapia menor, diariamente, junto com protocolo padrão de tratamento, no mesmo período que o grupo controle recebeu somente o protocolo padrão de tratamento. Foi notado em seus resultados que os indivíduos do grupo que recebeu o ozônio apresentaram melhora na intensidade da tosse e da falta de ar, diferente do grupo controle. O resultado obtido, teve como benefício, à não necessidade de internações em Unidade de Terapia Intensiva (UTI), assim como, a não utilização de oxigênio nem ventilação mecânica. Soma-se também, a diminuição da carga viral por consequência da redução dos infiltrados pulmonares e os danos causados aos tecidos do pulmão.

Hernández et al. (2021) relatam em seu estudo de caso feito em 18 pacientes infectados por COVID-19 e com pneumonia grave. Foi visto que, nove pacientes internados receberam tratamento padrão e nove receberam tratamento com autohemoterapia com ozônio, sendo administradas duas vezes ao dia a partir do dia da internação que durou em média quatro dias. Nos pacientes que receberam a terapia com ozônio houve uma diminuição da hipóxia tecidual, redução da hipercoagulação, da função imune moduladora com bloqueio de mediadores inflamatórios, aumento da ação fagocítica e diminuição da replicação viral.

No estudo de Peña-Lora et al. (2020) evidenciaram, através de um caso clínico de uma paciente idosa de 84 anos internada para o estudo clínico de 10 dias. A paciente apresentava febre, aumento da tosse e expectoração esbranquiçada, mialgia, odinofagia e fezes liquidas com aumento significativo, a partir desses sintomas, foi diagnosticada com infecção respiratória (confirmado por RT-PCR SARS-CoV-2) sendo levada ao setor de tratamento, conforme protocolo clínico. Esta paciente apresentava também patologias pré-existente, que favoreciam o agravamento do seu quadro clínico como hipertensão arterial, diabetes mellitus tipo 2, insuficiência cardíaca, cardiomiopatia hipertensiva, DPOC com oxigênio domiciliar, nódulo pulmonar maligno e síndrome lacunas motora sem sequelas. A paciente foi submetida a ozonioterapia via retal em uma concentração de $100 \mathrm{cc} / 35 \mu \mathrm{g} / \mathrm{ml}$ (cinco sessões, 1 sessão a cada 24hs). Após a aplicação das sessões foram realizados novos exames radiológicos e percebeu-se uma grande melhora, ou seja, a ozonioterapia teve um papel significativo na melhora do estado clínico da paciente (reduzindo a temperatura, diminuindo a necessidade de oxigênio e restabelecendo a saturação). Além da melhora clínica, por conta do uso ozonioterapia, a mesma, diminuiu o período de internação hospitalar.

Fernández-Cuadros et al. (2020) corroboram o estudo anterior, pois, através de um estudo prospectivo experimental feito em quatro pacientes graves com COVID-19 com resultados positivo para RT-PCR para SARS-CoV-2. Esses indivíduos foram diagnosticados com pneumonia moderada a grave, com febre e sintomas respiratórios moderados a grave, confirmados com lesões pulmonares com radiografia de tórax. Os pacientes que estavam internados e já haviam recebido tratamento farmacológico padrão com hidroxicloroquina, lopinavir/ritonavir e azitromicina, além de oxigênio terapêutico, anticorpos monoclonais anakinra (anti-interleucina 1 / anti-IL-1) e tocilizumabe (anti-interleucina 6 / anti-IL-6). Os pacientes foram submetidos a tratamento com ozônio. Deste modo, o tratamento foi administrado por via retal em um volume de $100 \mathrm{~mL}$ de 
ozônio, na concentração de $35 \mu \mathrm{g} / \mathrm{mL}$ por 5 a 10 dias, de acordo com a gravidade dos pacientes. Após 5 sessões de ozonioterapia intraretal observou-se melhora clínica da saturação e abastecimento de $\mathrm{O}_{2}$, as variáveis bioquímicas de inflamação (fibrinogênio, dímero D, ureia, ferritina, lactato desidrogenase / LDH, interleucina 6 / IL-6 e Proteína C - Reativa / CRP) e contagem de leucócitos e linfócitos houve uma melhora em todos os pacientes. Também houve melhora radiológica de pneumonia viral bilateral entre 1 e 2 com base na escala radiológica de Taylor. Outro ponto relevante citado pelos autores foi que o tratamento com ozônio não teve nenhum efeito colateral observado, exceto um moderado desconforto intestinal e uma sensação de edema, que diminuiu naturalmente.

Martínez-Sánchez et al. (2020) relatam em suas pesquisas que em uma terapia de longa duração por meio do ozônio é possível estimular uma adequação ao estresse oxidativo e, consequentemente, uma estabilidade do modo redox celular, a qual é um método essencial afim de impedir a replicação viral. O mecanismo contraditório ao qual o ozônio por ser um potente oxidante consegue ativar uma reação antioxidante, recentemente é comprovado não só na categoria proteômica bem como na genômica. O ozônio administrado em uma dose terapêutica, modula o fator nuclear KappB NF-אB e Nrf2 que leva ao equilíbrio do meio antioxidante. $\mathrm{O}$ estresse oxidativo e a imunidade inata possui uma função crucial nas vias de lesão pulmonar que monitoram a proporção da citotoxicidade pulmonar aguda no decorrer das infecções virais como na SARS-CoV / COVID-19.

Izadi et al. (2021) esclarecem que o Sistema Renina-Angiotensina-Aldosterona está interligado a patogênese da lesão pulmonar aguda grave. O SARS-CoV-2 se liga à Enzima Conversora de Angiotensina-2 (ACE2) através da proteína spike, deste modo a SARS CoV-2 utiliza-se desse receptor para entra no interior das células do hospedeiro. O SARS-CoV-2 ao se liga a este receptor, ativa Angiotensina II (AT2) nas células pulmonares ocasionando danos graves ao pulmão, pois a AT2 tem forte ação vasoconstritor e provoca estresse oxidativo. Em estudo recente observaram em pacientes graves por COVID-19 níveis séricos elevados de sNOX2-dp, um marcador de ativação da NADPH oxidase. Outra consequência relevante encontrada em pacientes com COVID-19 em comparação aos pacientes saudáveis, foi a diminuição da albumina sérica, fator que serve como barreira na defesa antioxidante. Há uma crescente literatura enfatizando que o estresse oxidativo preciso tem poder de ampliar as atividades antioxidantes. Deste modo, a terapia com ozônio possui função protetora para diminuir o estresse oxidativo através do equilíbrio redox para atividade oxidante.

É importante salientar que, a prática da ozonioterapia recentemente vem sendo muito explorada pela mídia brasileira e atualmente está tornando-se muito procurada para diversos fins terapêuticos. Porém, ainda há uma certa resistência para normatização da prática por partes dos órgãos regulamentadores, e das agências regulamentadoras de saúde, que ampare e proteja os profissionais habilitados em virtude dos riscos que possam vir a ocorrer aos pacientes.

Para Páez et al. (2020) é necessário que o sistema político realize as normativas com as medidas da prática da ozonioterapia, dentre estas, implementar a fiscalização confiável e correta dos profissionais competentes para prática desta técnica. Destaca-se que sem a padronização governamental, é possível que profissionais sem qualificação e desabilitado aplique o procedimento sem cumprimento dos protocolos e das condutas dessa prática, provocando desta forma reações adversas aos usuários. Todos esses fatores implicam na incredulidade tanto para quem aplica a técnica quanto para quem recebe. Desta forma, para realização de uma técnica segura é indispensável a prescrição do tratamento de forma responsável que comprove que a técnica é eficaz aos casos indicados.

Devido a isso, a Associação Brasileira de Ozonioterapia (ABOZ, 2019) demonstram que a normatização da aplicação da ozonioterapia em determinados conselhos de classe profissional vem evoluindo na expansão da utilização do ozônio medicinal. Como entidade encarregada por estabelecer normas para desempenho da profissão de forma regular, os conselhos definem os limites do exercício que os profissionais precisam para prosseguir, ou seja, delimita a prática de acordo com as diretrizes de cada classe profissional. Como médicos, enfermeiros, fisioterapeutas, dentistas, biomédicos e farmacêuticos, possuem distintas áreas de execução na ozonioterapia. 
Brasil (2020) discorre sobre o projeto de lei 1383/20 que sanciona a aplicação da ozonioterapia como terapia médica complementar, em todo país, para casos de COVID-19. Apesar da autora do projeto ressaltar que não existe indícios que se refere a eficácia da ozonioterapia na profilaxia ou recurso terapêutico para SARS-CoV-2. Porém, viabiliza que a comunidade médica use o tratamento quando considerar vantajoso, afinal, vem se tornando progressivamente pesquisada com o propósito de ajudar em várias patologias, dentre elas, a infecção por vírus. Apesar da terapia ser uma realidade em vários países, no Brasil o Conselho Federal de Medicina veta aos médicos esse tipo de indicação como tratamento dentro de consultórios e hospitais. A não ser em caráter experimental, seguindo protocolos clínicos e parâmetros estabelecidos pela Comissão Nacional de Ética em Pesquisa, a fim de proteger os pacientes que participarão do estudo.

Associação Brasileira de Ozonioterapia (ABOZ, 2020) reitera que em meio aos profissionais autorizados a praticarem a ozonioterapia está o fisioterapeuta através da Resolução 380/2010 do Conselho Federal de Fisioterapia, regulamentando o fisioterapeuta nas Práticas Integrativas e Complementares de Saúde (PICS), onde também engloba a ozonioterapia, abrangendo todos as vias de administração, contanto que o profissional seja habilitado ou tenha especialização na área. Além dos fisioterapeutas, os farmacêuticos também podem exercer a prática da ozonioterapia amparados pela Resolução nº 685,30 janeiro de 2020, na qual concede o farmacêutico de praticar a ozonioterapia clínica. Realizando consulta e anamnese farmacêutica, para identificar sinais e sintomas, detectando as necessidades do paciente, para somente assim fazer a prescrição farmacêutica em ozonioterapia.

Segundo Lima (2021) após realização de estudo no município de Pato na Paraíba observaram que os profissionais da saúde pouco conheciam da indicação da ozonioterapia para tratamento de diversas patologias. Em vista disso, evidenciaram que somente $32 \%$ dos entrevistados reconheciam hipoteticamente a técnica, destes, 5\% sabiam o suficiente, $79 \%$ pouco sabiam e $16 \%$ sabiam muito pouco. Sendo assim, $100 \%$ dos interrogados confirmaram que na unidade de saúde daquele município, não possuíam os equipamentos necessários e nem profissionais capacitados em ozonioterapia. Ao final dessa pesquisa, o ponto de vista dos profissionais a respeito da permissão da ozonioterapia no SUS foi que 47\% não conseguiram expor sua opinião, $38 \%$ acharam vantajosos e $15 \%$ acharam promissoras, porém com restrições.

\section{Conclusão}

De acordo com os estudos analisados observou-se que, o tratamento com a ozonioterapia, quando administrada em doses terapêuticas é capaz de modular o estresse oxidativo, atuando na liberação de citocinas e mediadores inflamatórios mantendo a homeostase no meio oxidativo e com isso há uma diminuição na replicação viral do SARS-CoV-2.

É visto que, no Brasil apenas algumas classes de profissionais da área da saúde são amparadas pelos órgãos regulamentadoras de saúde com as suas respectivas normativas e diretrizes. Dentre esses profissionais, destaca-se o profissional farmacêutico e o fisioterapeuta, que após sua capacitação está apto a realizar a ozonioterapia clínica sendo capaz de praticar todas as formas de aplicação da terapia com ozônio. Diante disso, a regulamentação da prática se faz necessário para que possam realizar a terapia com responsabilidade e segurança, tanto para os profissionais como para os usuários.

A ozonioterapia é amplamente utilizada em diversas patologias, sendo elas infecciosas ou não. Desta forma, a sua prática vem sendo aplicada em vários países com bastante êxito por ser eficaz, de baixo custo e com poucos efeitos adversos e ou tóxicos.

Observamos que a ozonioterapia pode ser utilizada de forma associada com outros fármacos, pois nas pesquisas realizadas até o momento foi constatado que houve uma melhora significativa no quadro clínico dos pacientes, não percebendo efeitos colaterais e sendo benéfico no tratamento da COVID-19.

Em estudos futuros é necessário um avanço nas pesquisas com maiores números de pacientes, doenças e fármacos a serem estudados para se aumentar a compreensão sobre a ozonioterapia e sua aplicação terapêutica de forma isolada e associada. 


\section{Referências}

ABOZ. (2019, julho 4). Regulamentação da Ozonioterapia e o que cada profissional pode fazer conforme o conselho de classe de cada um. https://www.aboz.org.br/noticias/regulamentacao-da-ozonioterapia-e-o-que-cadaprofissional-pode-fazer-conforme-o-conselho-de-classe-de-cada-um-/114/

ABOZ. (2020, junho 1). Os avanços da regulamentação da Ozonioterapia nos Conselhos de Classes. https://www.aboz.org.br/noticias/os-avancos-daregulamentacao-da-ozonioterapia-nos-conselhos-de-classes-/138/

Brasil, $n^{\circ}$ Resolução Nº 685, DE 30 De Janeiro De 2020, 267 (2020). https:/www.in.gov.br/en/web/dou/-/resolucao-n-685-de-30-de-janeiro-de-2020-255613547

Brasil. (2020). Projeto autoriza uso da ozonioterapia como tratamento complementar para Covid-19. Camara dos deputados. https://www.camara.leg.br/noticias/653829-projeto-autoriza-uso-da-ozonioterapia-como-tratamento-complementar-para-covid-19

Cattel, F., Giordano, S., Bertiond, C., Lupia, T., Corcione, S., Scaldaferri, M., Angelone, L., \& De Rosa, F. G. (2021). Ozone therapy in COVID-19: A narrative review. Virus Research, 291, 198207. https://doi.org/10.1016/j.virusres.2020.198207

Fernández-Cuadros, M. E., Albaladejo-Florín, M. J., Álava-Rabasa, S., Usandizaga-Elio, I., Martinez-Quintanilla Jimenez, D., Peña-Lora, D., Neira-Borrajo, I., López-Muñoz, M. J., Rodríguez-de-Cía, J., \& Pérez-Moro, O. S. (2020). Effect of Rectal Ozone (O3) in Severe COVID-19 Pneumonia: Preliminary Results. SN Comprehensive Clinical Medicine, 2(9), 1328-1336. https://doi.org/10.1007/s42399-020-00374-1

Ferreira, S. K. S., Cunha, I. P., Meneghim, M. C., \& De Checchi, M. H. R. (2020). Política Nacional de Práticas Integrativas e Complementares no Sistema Único de Saúde. Revista Faipe, 10(1), 21-39.

Galiè, M., Covi, V., Tabaracci, G., \& Malatesta, M. (2019). The Role of Nrf2 in the Antioxidant Cellular Response to Medical Ozone Exposure. International Journal of Molecular Sciences, 20(16), 4009. https://doi.org/10.3390/ijms20164009

Hernández, A., Viñals, M., Pablos, A., Vilás, F., Papadakos, P. J., Wijeysundera, D. N., Bergese, S. D., \& Vives, M. (2021). Ozone therapy for patients with COVID-19 pneumonia: Preliminary report of a prospective case-control study. International Immunopharmacology, 90, 107261. https://doi.org/10.1016/j.intimp.2020.107261

Izadi, M., Cegolon, L., Javanbakht, M., Sarafzadeh, A., Abolghasemi, H., Alishiri, G., Zhao, S., Einollahi, B., Kashaki, M., Jonaidi-Jafari, N., Asadi, M., Jafari, R., Fathi, S., Nikoueinejad, H., Ebrahimi, M., Imanizadeh, S., \& Ghazale, A. H. (2021). Ozone therapy for the treatment of COVID-19 pneumonia: A scoping review. International Immunopharmacology, 92, 107307. https://doi.org/10.1016/j.intimp.2020.107307

Lima, F. B. (2021). Ozonioterapia: Uma abordagem profissional e a aplicação da técnica em pacientes no Município de Patos/PB. Rev. Bras. de Educação e saúde. Município de Patos-PB, 11(1), 113-121.

Martínez-Sánchez, G., Schwartz, A., \& Di Donna, V. (2020). Potential Cytoprotective Activity of Ozone Therapy in SARS-CoV-2/COVID-19. Antioxidants, 9(5), 389. https://doi.org/10.3390/antiox9050389

Merhi, Z., Garg, B., Moseley-LaRue, R., Moseley, A. R., Smith, A. H., \& Zhang, J. (2019). Ozone therapy: A potential therapeutic adjunct for improving female reproductive health. Medical Gas Research, 9(2), 101-105. https://doi.org/10.4103/2045-9912.260652

Ornelas, P. T. S. F., Sousa, C. M. de, Silva, I. C. R. da, \& Fratelli, C. F. (2020). As evidências científicas da eficácia do uso da ozonioterapia frente à legislação sanitária brasileira. Revista de Divulgação Científica Sena Aires, 9(2), 320-326.

Páez, T. T., Pereira, P. A. I., Assis, L., dos Santos, L., \& Tim, C. R. (2020). Ozonioterapia E Seus Aspectos Controvertidos. Diálogos Interdisciplinares, 9(5), $1-21$.

Peña-Lora, D. Y., Albaladejo-Florín, M. J., \& Fernández-Cuadros, M. E. (2020). Uso de ozonoterapia rectal en paciente anciana con neumonía grave por COVID19. Revista Española de Geriatría y Gerontología, 55(6), 362-364. https://doi.org/10.1016/j.regg.2020.07.005

Piovesan, A., \& Temporini, E. R. (1995). Pesquisa exploratória: Procedimento metodológico para o estudo de fatores humanos no campo da saúde pública. Revista de Saúde Pública, 29(4), 318-325. https://doi.org/10.1590/S0034-89101995000400010

Ranaldi, G., Villani, E., \& Franza, L. (2020). Rationale for ozone-therapy as an adjuvant therapy in COVID-19: A narrative review. Medical Gas Research, 10(3), 0. https://doi.org/10.4103/2045-9912.289462

Rowen, R. J. (2019). Ozone and oxidation therapies as a solution to the emerging crisis in infectious disease management: A review of current knowledge and experience. Medical Gas Research, 9(4), 232-237. https://doi.org/10.4103/2045-9912.273962

Sagai, M., \& Bocci, V. (2011). Mechanisms of Action Involved in Ozone Therapy: Is healing induced via a mild oxidative stress? Medical Gas Research, 1(1), 29. https://doi.org/10.1186/2045-9912-1-29

Shah, M., Captain, J., Vaidya, V., Kulkarni, A., Valsangkar, K., Nair, P. M. K., \& Ganu, G. (2021). Safety and efficacy of ozone therapy in mild to moderate COVID-19 patients: A phase 1/11 randomized control trial (SEOT study). International Immunopharmacology, 91, 107301. https://doi.org/10.1016/j.intimp.2020.107301

Silva, T. C., Shiosi, R. K., \& Raineri Neto, R. (2018). Ozonioterapia: Um tratamento clínico em ascensão na medicina veterinária-revisão de literatura. R. cient. eletr. Med. Vet.

Souza, M. T. de, Silva, M. D. da, \& Carvalho, R. de. (2010). Integrative review: What is it? How to do it? Einstein (São Paulo), 8(1), 102-106. https://doi.org/10.1590/s1679-45082010rw1134 